\title{
The Kinetics of Electron Transfer Reaction of Methylene Blue and Titanium Trichloride in different Solvents
}

\author{
Rehana Saeed* and Syed Muhammad Saqib Nadeem" \\ *Department of Chemistry, University of Karachi, Karachi-75270, Pakistan. \\ E-mail:*rehana_saeed01@hotmail.com \\ *Department of Chemistry, University of Karachi, Karachi-75270, Pakistan. \\ E-mail: "saqib.chemist@gmail.com
}

\section{ABSTRACT}

The kinetics of the electron transfer reaction of methylene blue and titanium trichloride was studied in water and aqueous alcoholic solvents at various temperatures by spectrophotometry. The rate of reaction was observed by taking change in absorbance as a function of time at $\lambda_{\max } 660 \mathrm{~nm}$. The reaction is pseudo-first order, dependent on concentration of titanium trichloride at fixed concentration of methylene blue.

The effect of solvent was studied in the $\mathrm{pH} / \mathrm{H}_{\circ}$ range from 4 to 7 . It was observed that the rate of reaction increased with increase in polarity of the reaction medium. The rate of reaction was high in acidic condition and decreased with further increase in hydrogen ions activity. The increase in temperature increased the rate of electron transfer reaction of methylene blue and titanium trichloride. Activation energy $\left(E_{a}\right)$ was calculated by Arrhenius relation. The absence of any reaction intermediate was confirmed by spectroscopic and kinetic investigations. A plausible mechanism for the reaction in line with outer-sphere reaction pathway has been proposed. Thermodynamic parameters such as activation energy ( $\left.E_{a}\right)$, enthalpy change $(\Delta H)$, free energy change $(\Delta G)$ and entropy change $(\Delta S)$ were also evaluated.

Key Words: Methylene Blue, Titanium Trichloride, Alcohols, Kinetics, Thermodynamics

ACADEMIC DISCIPLINE AND SUB-DISCIPLINES

Physical Chemistry

\section{SUBJECT CLASSIFICATION}

Spectrophotometry; Dyes.

\section{TYPE (METHOD/APPROACH)}

Kinetic Experimental Study.

\section{Council for Innovative Research}

Peer Review Research Publishing System

\section{Journal: Journal of Advances in Chemistry}

Vol. 6, No. 2

editor@cirworld.com

www.cirworld.com, member.cirworld.com 


\section{INTRODUCTION}

The methylene blue (3,7-Bis-dimethylamino phenazo-thionium chloride) is a water soluble organic, polyaromatic and heterocyclic compound and is chemically named as methylthioninium chloride. It is a powerfull cationic dye having $\lambda_{\max }$ at 660 $\mathrm{nm}$. The structure of methylene blue is shown below.

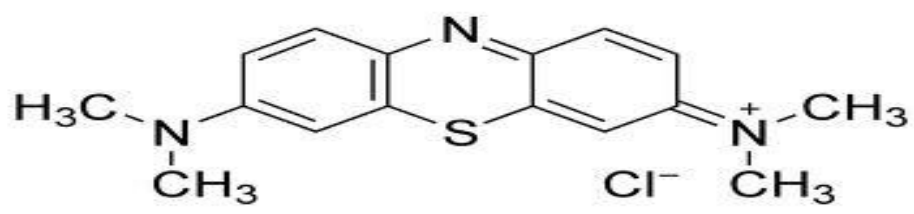

\section{Methylene Blue}

The phenothiazine dyes have a variety of applications such as in dyeing of clothes, coloring of paper, manufacturing of colored plastics, optical data storage devices, data recording holographic industries, in pharmaceutical preparations as an antiseptic and in food industry but on the other hand; they are toxic and carcinogenic in nature. The colorimetric indicators of oxygen used in food industry are based upon a chemical reaction between methylene blue and glucose present in the food [1]. Methylene blue can be used in photodynamic therapy of tumors and also RNA viruses can be inactivated by treatment with methylene blue molecules [2].

The non-protonated form of methylene blue is colored but it can be easily reduced reversibly to colorless leuco-methylene blue by an electron transfer reaction. A typical reaction illustrating the reduction of methylene blue is given below.

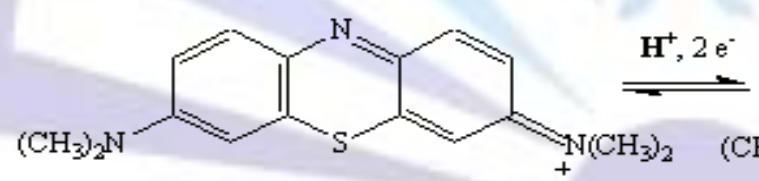

Methylene Blue
Leuco-Methylene Blue

The reduction of dyes has been practically used in textile industries for the decolorization of industrial waste effluents containing dyes. The reduction process of dyes was carried out by various reductants such as mercaptoacetic acid, EDTA, formaldehyde, amines, sugars, potassium iodide and sulfur compounds $[3,4,5,6,7]$. Methylene blue can be photochemically degraded by $\mathrm{TiO}_{2}$ in the presence of UV light and $\mathrm{H}_{2} \mathrm{O}_{2}$ to comparatively less toxic products on an industrial scale [8, 9]. The photo degradation of methylene blue can be accomplished using a mixed catalytic system consisting of $\mathrm{ZnO} / \mathrm{TiO}_{2}[10]$. 
The phenomenon of solvatochromism and preferential solvation of dyes in binary solvent has been a topic of interest for many researchers [11]. The electron transfer reaction of methylene blue with 2-Thiobarbituric Acid can be used as an effective degradation pathway for barbiturate drugs which are used for the central nervous system [12]. The current research has shown that methylene blue can also be reduced potentiometrically at carbon electrode due to change in applied voltage [13].

The present work presents the kinetic study of electron transfer reaction between methylene blue and titanium trichloride. The effect of temperature, hydrogen ion activity, and concentration of titanium trichloride on the electron transfer reaction has been studied in water and different aqueous alcoholic solvents by spectrophotometry.

\section{EXPERIMENTAL}

\subsection{Materials}

Methylene blue (99.99\%) of E-Merck, Hydrochloric Acid, Acetic Acid, Sodium Acetate, Sodium Hydroxide, Methanol, Ethanol, 2-Propanol and Butanol of BDH were used without any further processing. A $15 \% \mathrm{w} / \mathrm{w}$ stock solution of titanium trichloride of E-Merck with density of $1.185 \mathrm{~g} / \mathrm{cm}^{3}$ was used for the preparation of different concentrations of titanium trichloride $\left(2 \times 10^{-4}\right.$ to 5 $\left.\times 10^{-3} \mathrm{~mol} . \mathrm{dm}^{-3}\right)$. The acetate buffer solutions were used to maintain the $\mathrm{pH} / \mathrm{H}_{0}$ of reaction mixture in the range of 4.0 to 7.0 . Freshly prepared double distilled water having conductance $\left(6.0 \times 10^{-2} \mu \mathrm{S} . \mathrm{cm}^{-1}\right)$ was used for preparation of all solutions. The absorbance of reaction mixture was measured by UV-visible spectrophotometer (UV-160). A quartz cell having path length 1.0 $\mathrm{cm}$ with capacity of $3 \mathrm{~mL}$ was used to measure the absorbance of reaction mixture. A thermostatic water bath (circulator, model, YCW01, made in Taiwan) was used for maintaining the desired temperature of reaction mixture throughout the experiment.

\subsection{Methods}

The spectra of methylene blue solutions were taken in water and different aqueous-alcoholic solvents and the $\lambda_{\text {max }}$ of methylene blue was determined. The rate for the electron transfer reaction of methylene blue and titanium trichloride was studied by measuring the change in absorbance with respect to time using spectrophotometry. The absorbance data was used to calculate the rate of reaction. The effect of solvent, temperature and concentration of titanium trichloride on rate of reaction was studied. The absorbance of reaction mixture was measured at temperatures 298 to $318 \mathrm{~K}$ and the effect of temperature on the electron transfer reaction between methylene blue and titanium trichloride was determined. The concentration of methylene blue was fixed at $1.0 \times 10^{-5}$ mol. $\mathrm{dm}^{-3}$ during the kinetic study while the concentration of titanium trichloride was varied from $2.0 \times 10^{-4}$ to $1.0 \times 10^{-3} \mathrm{~mol}_{\mathrm{dm}}^{-3}$ The effect of $\mathrm{pH}$ was determined by carrying out the reaction at $\mathrm{pH}$ values of 4.0 , 5.0, 6.0 and 7.0 in water and different aqueous-alcoholic solvents by change in absorbance of the reaction mixture. The pH in 
water was measured by Orion $\mathrm{pH}$ meter while the hydrogen ion activity in aqueous alcoholic solvents was determined in terms of Hammet acidity function $\left(\mathrm{H}_{0}\right)$ by measuring the absorbance of acridine orange solutions.

$H_{0}=\mathrm{pK}_{\mathrm{a}}+\log \mathrm{A}_{1}-\mathrm{A} / \mathrm{A}-\mathrm{A}_{2}$

Where $\mathrm{pK}_{\mathrm{a}}$ is the acid dissociation constant of acridine orange $\left(\mathrm{pK}_{\mathrm{a}}=5.45\right)$, ' $\mathrm{A}_{1}$ ' and ' $\mathrm{A}_{2}$ ' is the absorbance of acridine orange in extreme acidic and basic solutions and ' $A$ ' is the absorbance of a solution of intermediate acidity $[4,7]$.

\section{RESULTS AND DISCUSSION}

The spectral analysis of methylene blue was done in different solvents in the presence and absence of titanium trichloride to determine the effect of different solvents and titanium trichloride on the absorption spectrum. The rate of reaction for the electron transfer reaction of methylene blue and titanium trichloride was determined by spectrophotometric analysis of change in absorbance with respect to time in water and aqueous alcoholic solvents.

\subsection{Spectral Analysis}

The values of $\lambda_{\max }$, molar absorptivity coefficient $(\varepsilon)$ and transition energy $\left(\mathrm{E}_{\mathrm{T}}\right)$ of methylene blue in water and aqueous alcoholic solvents are reported in Table 1. The $\lambda_{\max }$ of methylene blue was used for the calculation of transition energy using the given equation:

$\mathrm{E}_{\mathrm{T}}=\mathrm{h} \mathrm{c} \mathrm{N}_{\mathrm{A}} / \lambda_{\max }$

(2)

Where $\mathrm{h}$ is the Planck's constant, $\mathrm{c}$ is the speed of light and $\mathrm{N}_{\mathrm{A}}$ is the Avogadro's number [7]. 
Table 1. $\lambda_{\max }$, Molar Absorptivity and Transition Energy of Methylene Blue in different solvents

\begin{tabular}{|l|c|c|c|c|}
\hline \multicolumn{1}{|c|}{ Solvent } & Absorbance & $\lambda_{\max }(\mathrm{nm})$ & $\begin{array}{c}\text { Molar Absorptivity }(\varepsilon) \times \mathbf{1 0}^{4} \\
\left(\mathrm{~mol}^{-1} \cdot \mathrm{dm}^{\mathbf{3}} \cdot \mathrm{cm}^{-1}\right)\end{array}$ & $\begin{array}{c}\text { Transition Energy (E } \\
\left(\mathrm{KJ}_{\mathrm{T}}\right)\end{array}$ \\
\hline Water & 1.134 & 660 & 6.790 & 181.374 \\
\hline $\mathbf{5 0 \%}$ Aq. Methanol & 1.400 & 661 & 8.415 & 181.100 \\
\hline $\mathbf{5 0 \%}$ Aq. Ethanol & 1.467 & 662 & 8.785 & 180.827 \\
\hline $\mathbf{5 0 \%}$ Aq. 2-Propanol & 1.722 & 662 & 10.310 & 180.827 \\
\hline $\mathbf{5 \%}$ Aq. Butanol & 1.229 & 667 & 7.359 & 179.471 \\
\hline
\end{tabular}

The transition energy $\left(E_{T}\right)$ increased with increasing solvent polarity which means that the ground state of methylene blue is more polar than its excited states. The polar ground state becomes more stabilized in the presence of a solvent having greater polarity as compared to a non-polar solvent. This stabilization of polar ground state increases the energy difference between the ground state and the excited state which is exhibited as a hypochromic shift in the spectrum of methylene blue with increasing solvent polarity [9]. The absorption spectra of methylene blue in different solvents are shown in Figure 1.

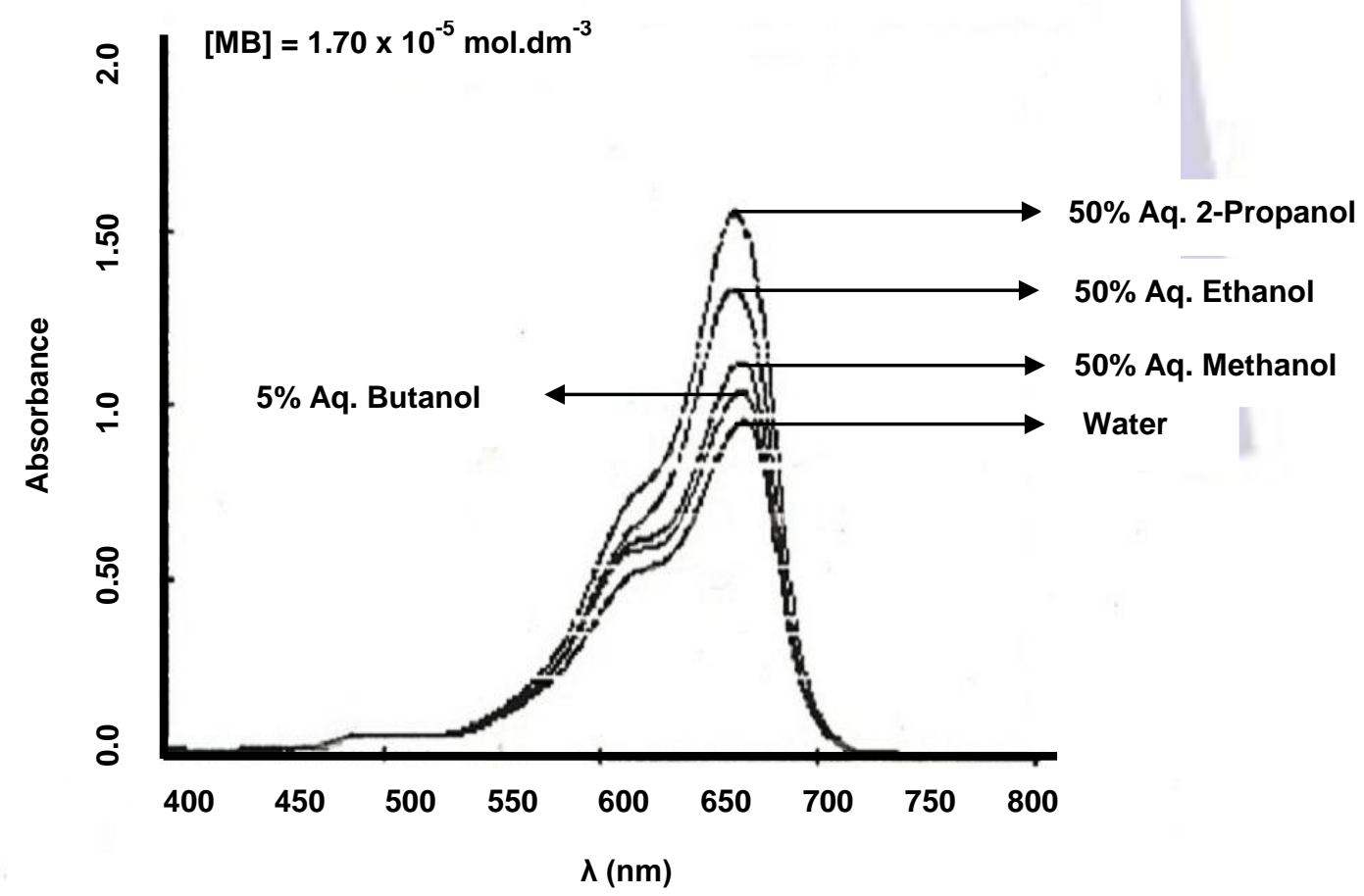

Figure 1. UV-Visible spectra of methylene blue in different solvents 
The spectrum shows a small shift in the $\lambda_{\max }$ and molar absorptivity of methylene blue in different solvents. The different type of electronic transitions effect the $\lambda_{\max }$ of a solute depending upon the solvent in which the solute is dissolved due to the phenomenon of preferential solvation [8]. It was observed that an increase in chain length of alcohol molecule increases the intensity of the absorption spectrum due to preferential solvation of methylene blue molecules in cationic form in the alcohol rich region since the water molecules in this region are strongly interrelated with each other via hydrogen bonding. Furthermore, the basicity of alcohol molecules increases with increase in carbon chain length which makes it to compete efficiently with the $\mathrm{MB}^{+}$species for the water molecules; thereby hindering the interaction between $\mathrm{MB}^{+}$species and water molecules. Also, a hypsochromic shift is observed with increase in chain length of alcohol molecules caused by a decrease in energy difference between ground and excited states. A hyperchromic shift in the absorption spectrum was observed with increase in chain length of alcohol molecules from water to $50 \%$ aqueous 2-propanol. However, a hypochromic shift was observed in the spectrum of methylene blue in $5 \%$ aqueous butanol with respect to other aqueous alcoholic solvents. This is due to extremely low miscibility of butanol in water which minimizes the phenomenon of preferential solvation in $5 \%$ aqueous butanol as compared to $50 \%$ aqueous methanol, $50 \%$ aqueous ethanol and $50 \%$ aqueous 2 -propanol [7, 11$]$.

The UV-Visible spectra of methylene blue were taken in water in the presence and absence of titanium trichloride and the effect of titanium trichloride on the intensity of absorption spectrum was observed. These spectra are shown in Figure 2.

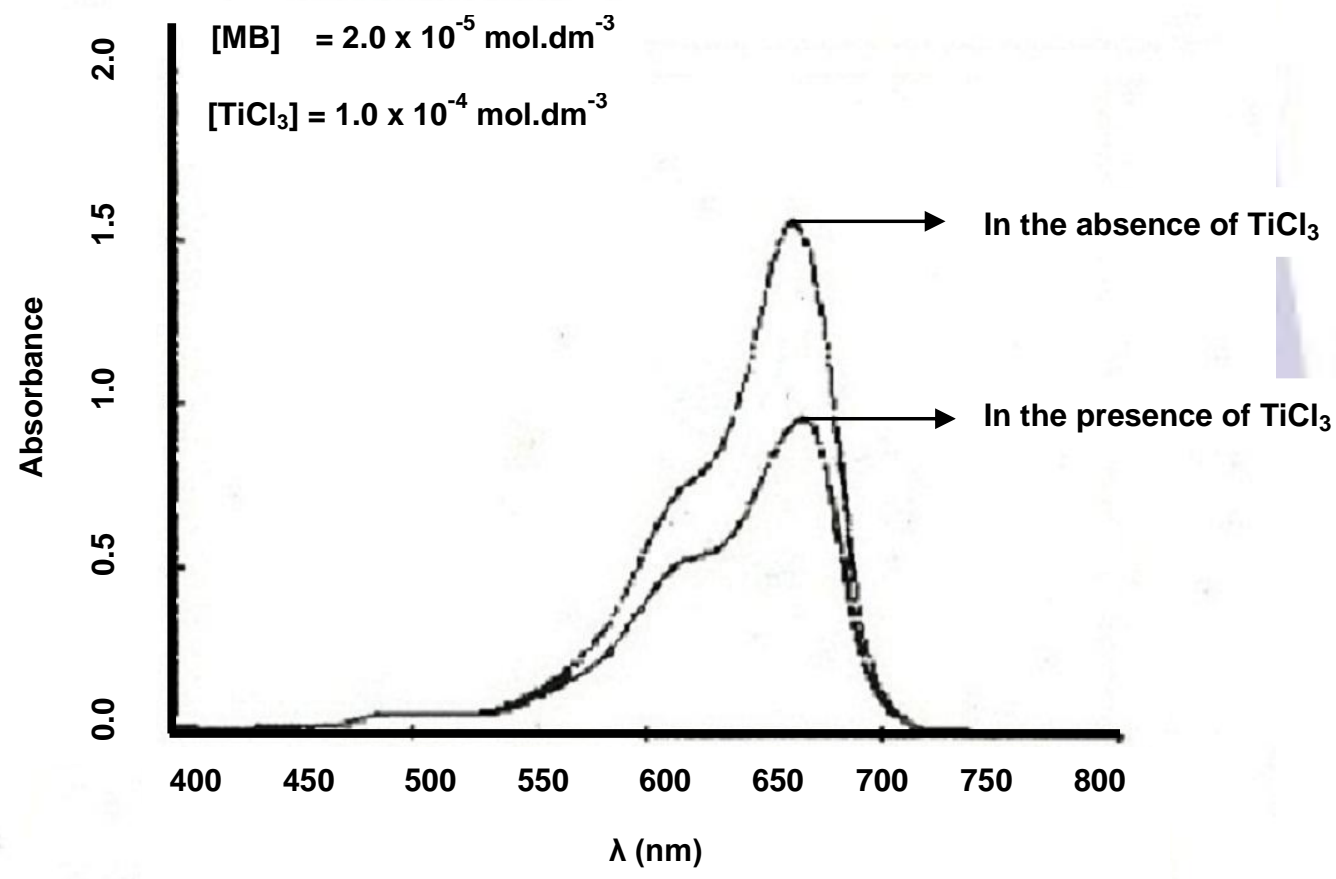

Figure 2. UV-Visible spectra of methylene blue in water 
These spectra show a difference in the intensity of absorption spectrum due to the effect of titanium trichloride which reduces some molecules of methylene blue to leucomethylene blue which has its absorption maximum in the UV region at $256 \mathrm{~nm}$ and therefore does not contributes in the absorption at $660 \mathrm{~nm}$. The spectrum of leuco-methylene blue in water is like a bellshaped curve and its intensity is greater than methylene blue. The spectrum is shown in Figure 3 . The peak absorption of leuco-methylene blue is at $256 \mathrm{~nm}$. The formation of leuco-methylene blue involves the protonation of nitrogen atom on the central ring of methylene blue molecule accompanied by a shift in the location of double bonds inside the aromatic rings. This structural change shifts the $\lambda_{\max }$ of the molecule from visible to UV region.

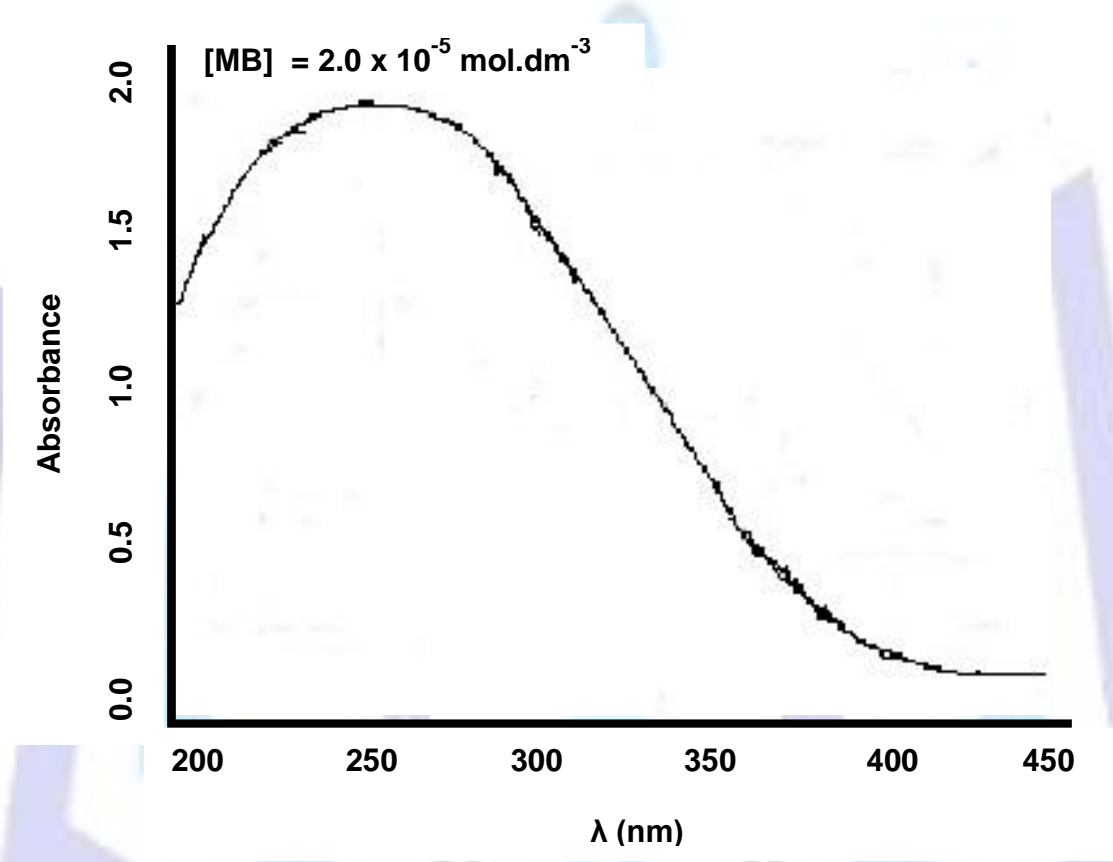

Figure 3. UV-Visible spectrum of leuco-methylene blue in water

\subsection{Study of Rate of Reaction}

The rate of reaction for the electron transfer reaction of methylene blue and titanium trichloride was studied at different experimental conditions by recording the change in absorbance of the reaction mixture with respect to time. A representative plot is given in Figure 4. The reaction is very fast as is evident from the rapid change in absorbance of reaction mixture. The aqueous alcoholic solvents have a lower dielectric constant as compared to water and hence, the reaction takes a little more time for completion than in water. The rate of reaction was relatively higher in water as compared to aqueous alcoholic solvent which shows that the formation of leuco-methylene blue is extremely fast in solvent of high polarity. 


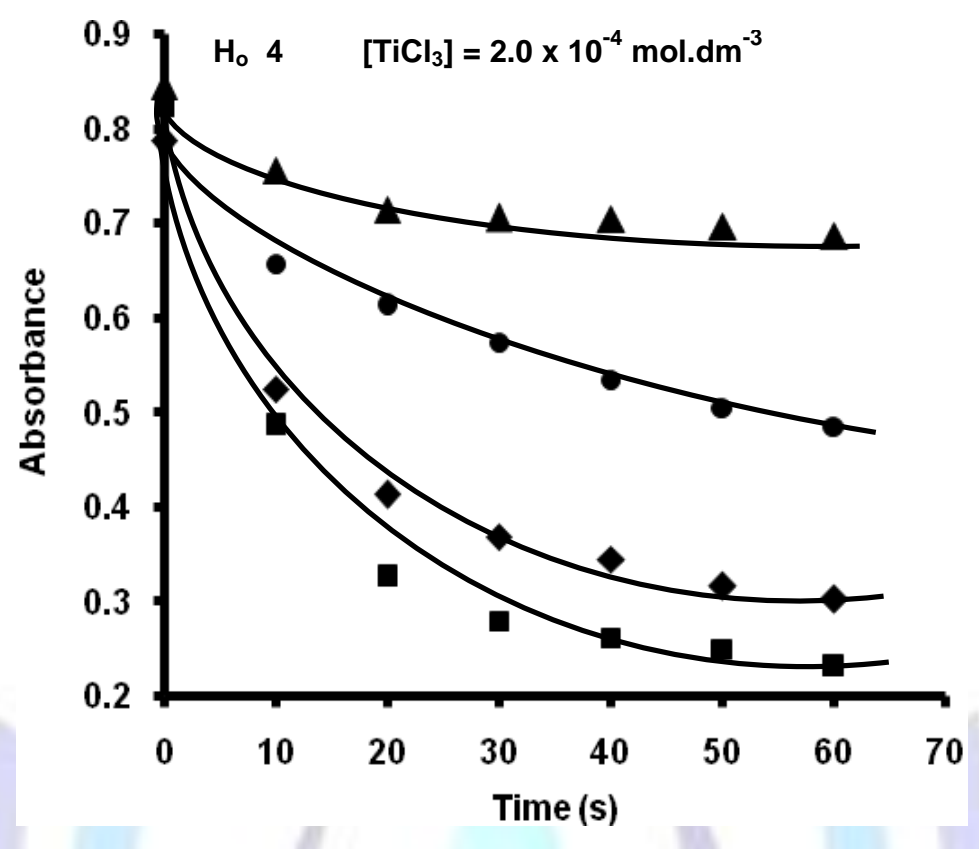

Figure 4. A plot of absorbance vs time for the electron transfer reaction in different solvents at $298 \mathrm{~K}$

A reversible oxidation process was also observed in water due to dissolved oxygen in the reaction mixture. The rate of reaction also decreased in aqueous alcoholic solvents with an increase in carbon chain length of alcohol molecules due to decreased polarity of the solvent and decrease in frequency of collisions between reactant molecules due to steric hinderance. The rate of reaction decreased from $50 \%$ aqueous methanol to $50 \%$ aqueous 2 -propanol with the exception of $50 \%$ aqueous ethanol. The rate of reaction increased in $5 \%$ aqueous butanol because although butanol is the most non-polar of all the alcohols used in the experiment, it is used as $5 \%$ aqueous butanol due to extremely low miscibility of butanol in water. Hence, $5 \%$ aqueous butanol has a higher dielectric constant than 50\% aqueous 2-propnaol and an increases in rate of reaction is observed. The results are tabulated in Table 2.

\subsection{Effect of $\mathrm{TiCl}_{3}$ Concentration on Rate of Reaction}

The increase in concentration of titanium trichloride increased the rate of electron transfer reaction of methylene blue and titanium trichloride. The titanium chloride is extremely fast in its reducing action and converts the colored form of methylene blue to its colorless form, the leucomethylene blue by the addition of a proton. The rate of reaction follows a linear relationship with the concentration of titanium trichloride as shown in Figure 5. 
Table 2. Rate of Reaction for the Electron Transfer Reaction of Methylene Blue and Titanium Trichloride at $298 \mathrm{~K}$

\begin{tabular}{|c|c|c|c|c|}
\hline \multirow[t]{4}{*}[\mathrm{TiCl}_{3}]{$/ \mathrm{mol} \mathrm{dm}^{-3}$} & \multicolumn{4}{|c|}{ Rate of Reaction (mol.dm $\left.{ }^{3} \cdot \mathrm{s}^{-1}\right) \times 10^{2}$} \\
\hline & \multicolumn{4}{|c|}{$\mathrm{pH} / \mathrm{H}_{\mathrm{o}}$} \\
\hline & 4.0 & 5.0 & 6.0 & 7.0 \\
\hline & \multicolumn{4}{|c|}{ Water } \\
\hline $2.0 \times 10^{-4}$ & 4.430 & 5.500 & 2.900 & 2.150 \\
\hline $4.0 \times 10^{-4}$ & 5.100 & 6.200 & 4.300 & 3.050 \\
\hline $6.0 \times 10^{-4}$ & 6.180 & 6.880 & 5.000 & 4.200 \\
\hline $8.0 \times 10^{-4}$ & 6.930 & 7.500 & 5.750 & 5.150 \\
\hline \multirow[t]{2}{*}{$10.0 \times 10^{-4}$} & 7.380 & 8.150 & 6.070 & 5.420 \\
\hline & \multicolumn{4}{|c|}{$50 \%$ Aqueous Methanol } \\
\hline $2.0 \times 10^{-4}$ & 3.180 & 4.400 & 1.800 & 1.220 \\
\hline $4.0 \times 10^{-4}$ & 4.580 & 5.480 & 3.400 & 2.860 \\
\hline $6.0 \times 10^{-4}$ & 5.310 & 6.100 & 4.430 & 3.860 \\
\hline $8.0 \times 10^{-4}$ & 5.830 & 6.550 & 5.200 & 4.710 \\
\hline $10.0 \times 10^{-4}$ & 6.310 & 7.200 & 5.580 & 5.210 \\
\hline & \multicolumn{4}{|c|}{$50 \%$ Aqueous Ethanol } \\
\hline $2.0 \times 10^{-4}$ & 3.680 & 5.300 & 2.080 & 1.430 \\
\hline $4.0 \times 10^{-4}$ & 4.830 & 6.000 & 4.080 & 3.000 \\
\hline $6.0 \times 10^{-4}$ & 5.920 & 6.620 & 4.830 & 4.130 \\
\hline $8.0 \times 10^{-4}$ & 6.840 & 7.200 & 5.500 & 5.130 \\
\hline $10.0 \times 10^{-4}$ & 7.100 & 7.600 & 5.830 & 5.300 \\
\hline & \multicolumn{4}{|c|}{$50 \%$ Aqueous 2-Propanol } \\
\hline $2.0 \times 10^{-4}$ & 2.680 & 4.150 & 1.510 & 1.050 \\
\hline $4.0 \times 10^{-4}$ & 4.200 & 5.100 & 2.860 & 2.450 \\
\hline $6.0 \times 10^{-4}$ & 5.010 & 5.750 & 3.840 & 3.340 \\
\hline $8.0 \times 10^{-4}$ & 5.550 & 6.340 & 4.560 & 4.370 \\
\hline \multirow[t]{2}{*}{$10.0 \times 10^{-4}$} & 5.960 & 6.850 & 5.030 & 4.650 \\
\hline & \multicolumn{4}{|c|}{$5 \%$ Aqueous Butanol } \\
\hline $2.0 \times 10^{-4}$ & 2.890 & 4.250 & 1.680 & 1.130 \\
\hline $4.0 \times 10^{-4}$ & 4.300 & 5.250 & 3.100 & 2.700 \\
\hline $6.0 \times 10^{-4}$ & 5.190 & 5.900 & 4.050 & 3.650 \\
\hline $8.0 \times 10^{-4}$ & 5.610 & 6.450 & 4.850 & 4.500 \\
\hline $10.0 \times 10^{-4}$ & 6.150 & 7.000 & 5.220 & 5.000 \\
\hline
\end{tabular}




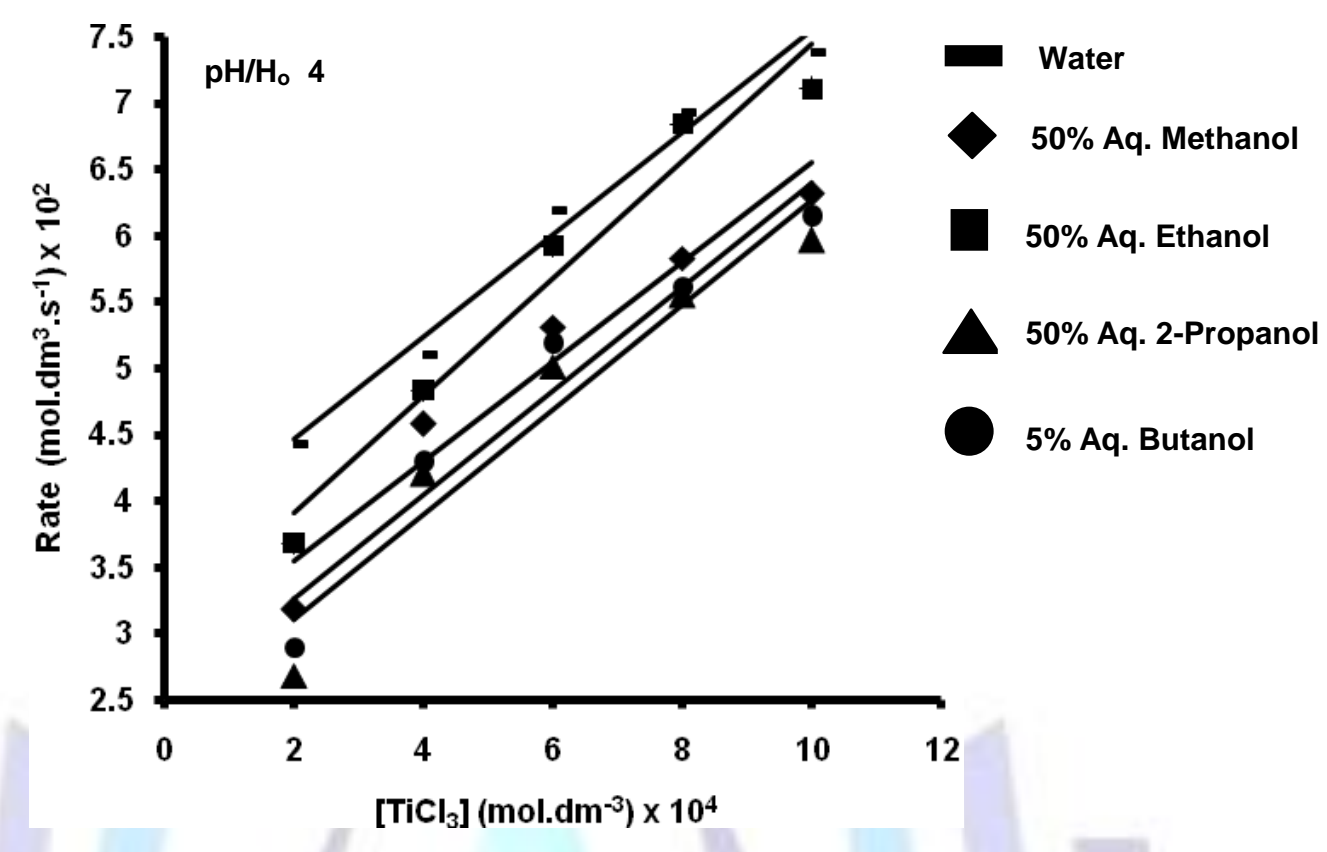

Figure 5. A plot of the rate of reaction vs concentration of titanium trichloride in different solvents at 298

\subsection{Effect of Hydrogen Ion Activity on Rate of Reaction}

The hydrogen ion activity of the reaction medium shows an effect on the rate of electron transfer reaction of methylene blue and titanium trichloride. The rate of reaction is relatively higher in acidic $\mathrm{pH} / \mathrm{H}_{\circ}$ range and decreased in basic range. The rate of reaction was high at $\mathrm{pH} / \mathrm{H}_{0} 5$. The effect of $\mathrm{pH}$ on rate of reaction can be explained by the fact that as the $\mathrm{pH}$ of the reaction mixture was increased above 5, the dye molecules may have lost their positively charged state and this resulted in a decrease in rate of reaction. At $\mathrm{pH} 4$, the slow rate of reaction as compare to $\mathrm{pH} 5$ can be due to the presence of a large number of protons in the medium and hence, the reaction between titanium trichloride and water molecules that leads to the abstraction of proton from water molecules is inhibited [14]. A plot for the effect of hydrogen ion activity is given in Figure 6.

\subsection{Effect of Methylene Blue Concentration on Rate of Reaction}

The effect of the concentration of methylene blue on the rate of reaction was determined at different concentrations of methylene blue. It was observed that the rate of reaction initially increased insignificantly up to a certain concentration of methylene blue and then it decreased very rapidly. At higher concentration of methylene blue, the molecules are in the form of clusters which resists the approach of titanium trichloride molecules and hence, the rate of reaction decreases. So the reaction was studied at fixed concentration of methylene blue. 


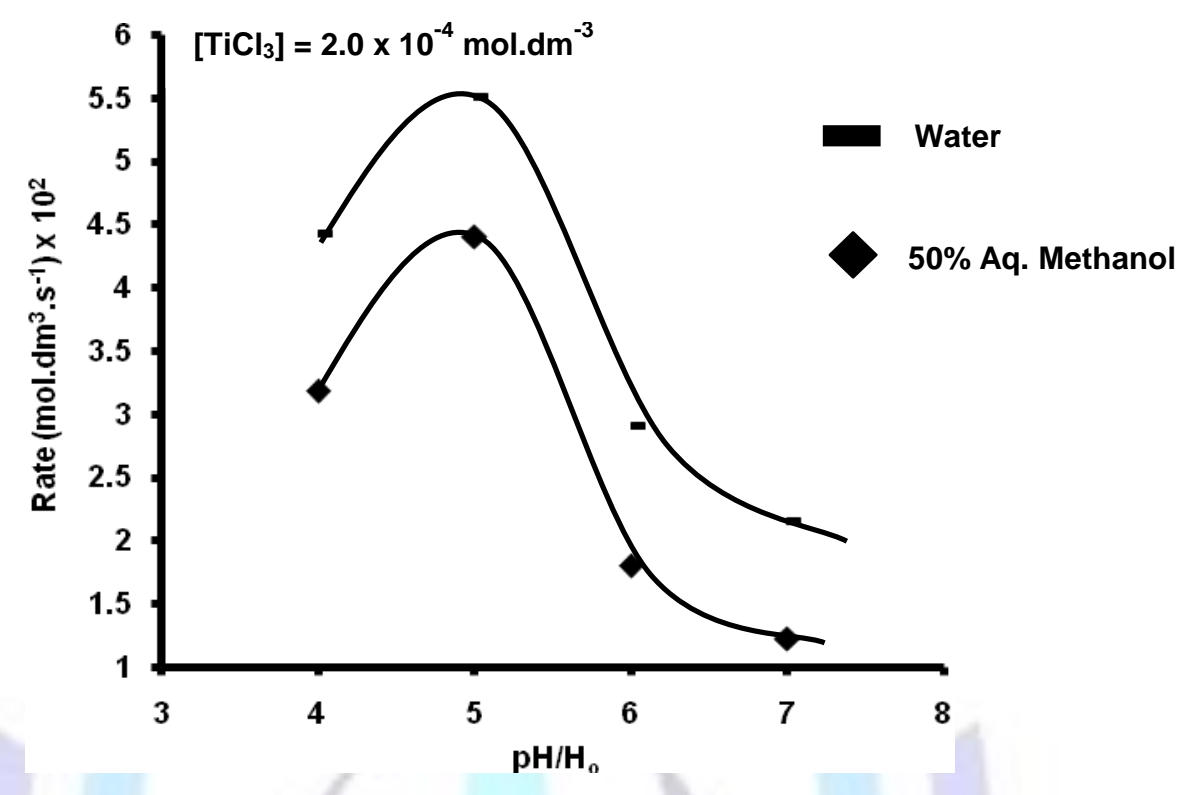

Figure 6. A plot of the rate of reaction as a function of $\left(\mathrm{pH} / \mathrm{H}_{\mathrm{o}}\right)$ of reaction mixture in different solvents at $298 \mathrm{~K}$

\subsection{Kinetic Study}

The kinetics of electron transfer reaction of methylene blue and titanium trichloride was determined in water and aqueous alcoholic solvents at temperatures of 298 to $318 \mathrm{~K}$. The change in absorbance was recorded as a function of time at a fixed concentration of methylene blue and at various concentrations of titanium trichloride. The plot of log $\left(A_{t}-A_{\infty}\right)$ versus time shows that the electron transfer reaction of methylene blue and titanium trichloride is a pseudo-first order reaction [15]. The slope of the plot gives the value of rate constant $(\mathrm{k})$. A representative plot is given in Figure 7 . The plot of log $\mathrm{k}$ against log $\left[\mathrm{TiCl}_{3}\right]$ in Figure 8 gives a straight line with slope of 0.993 , showing a first order dependence of reaction rate on [ $\left.\mathrm{TiCl}_{3}\right]$.

The values of rate constants for the reaction are tabulated in Table 3 . The rate constant was affected by the polarity of the reaction medium. The rate constant increased with increase in polarity of the reaction medium due to an increase in attraction between charged reactant species. The order of polarity of the solvents is:

Water $>50 \%$ Aq. Methanol $>50 \%$ Aq. Ethanol $>5 \%$ Aq. Butanol $>50 \%$ Aq. 2-Propanol 


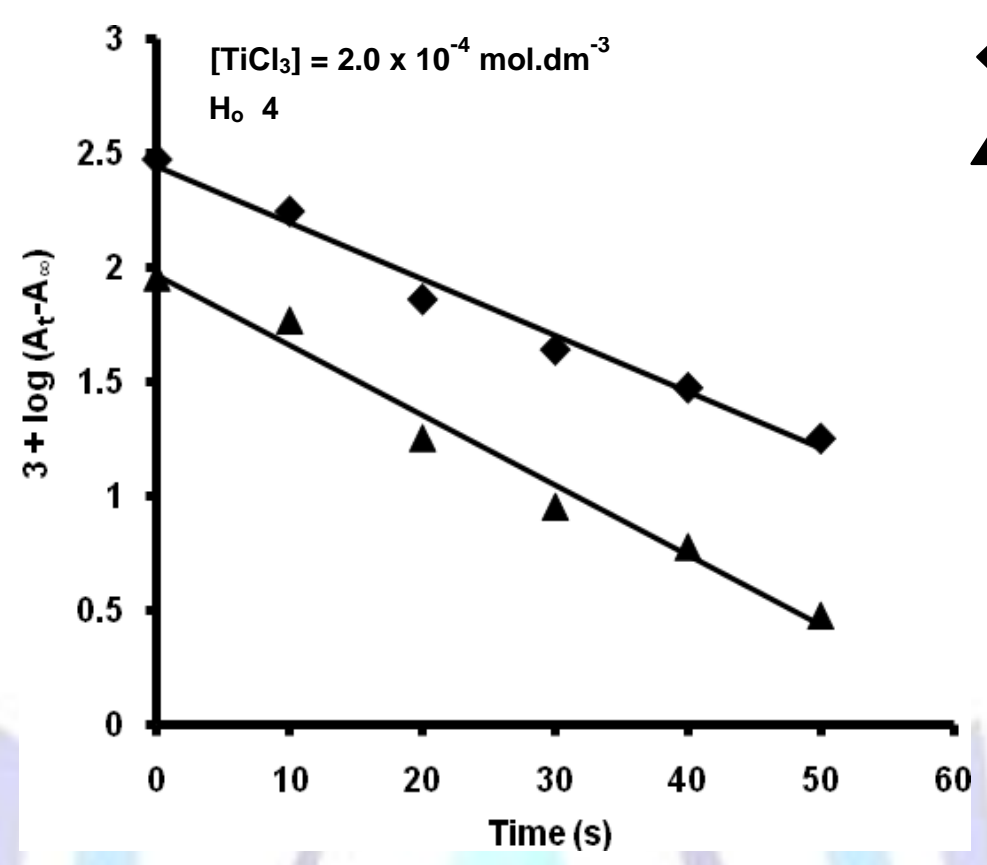

$50 \%$ Aq. Methanol

$50 \%$ Aq. 2-Propanol

Figure 7. Pseudo-first order plot for the Electron Transfer Reaction at $298 \mathrm{~K}$

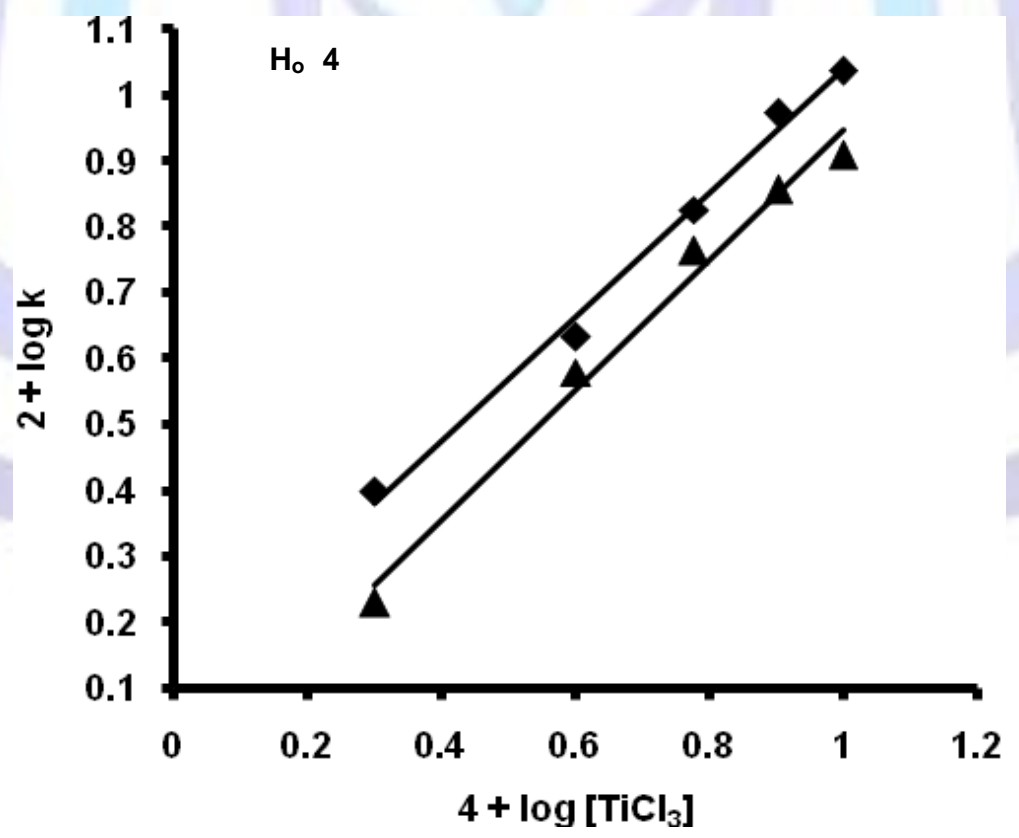

Figure 8. Plot of $\log \mathrm{k}$ versus $\log \left[\mathrm{TiCl}_{3}\right]$ for the Electron Transfer Reaction at $298 \mathrm{~K}$ 
Table 3. Rate Constants for the Electron Transfer Reaction of Methylene Blue and Titanium Trichloride

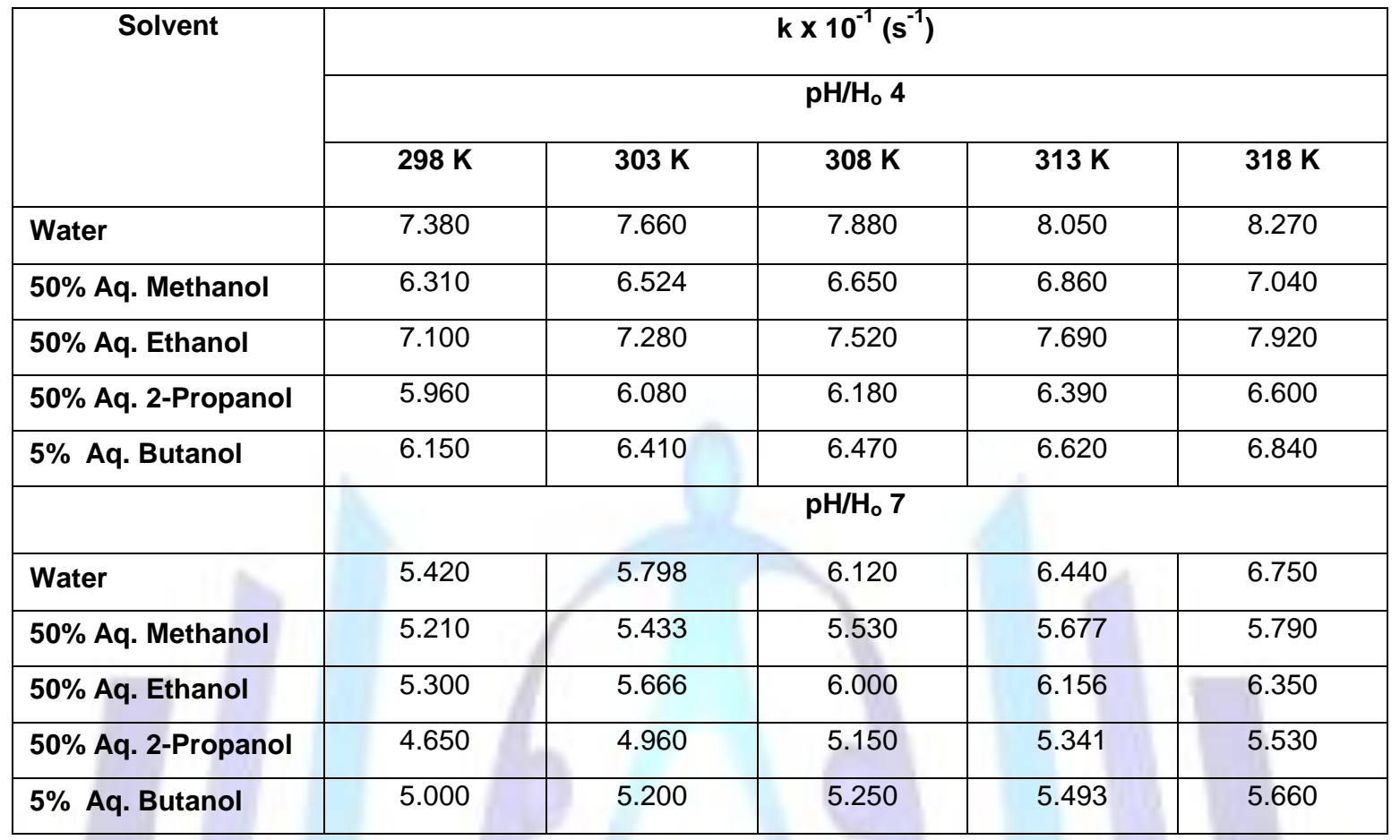

The rate constant decreased as the concentration of titanium trichloride in the reaction mixture increased. This is explained by the fact that at the start of reaction the rate of formation of product is high but as the reaction proceeds the concentration of product in the reaction mixture increases which causes the reaction to proceed in the backward direction. Hence, a decrease in rate constant of reaction is observed as the concentration of titanium trichloride is increased. The variation in the value of rate constant as a function of concentration of titanium trichloride in different aqueous solvents is shown in Figure 9.

\subsection{Analysis for Formation of Intermediate Complex}

The formation of any intermediate complex during the reaction was determined by the electronic spectra of partially reduced methylene blue solution which showed no change in $\lambda_{\max }$ of solution. The only two peaks observed were that of methylene blue $(660 \mathrm{~nm})$ and that of leuco-methylene blue $(256 \mathrm{~nm})$. The Michealis-Menten plot had a positive intercept which confirmed the absence of any intermediate species [16]. The Michealis-Menten plot is shown in Figure 10. 


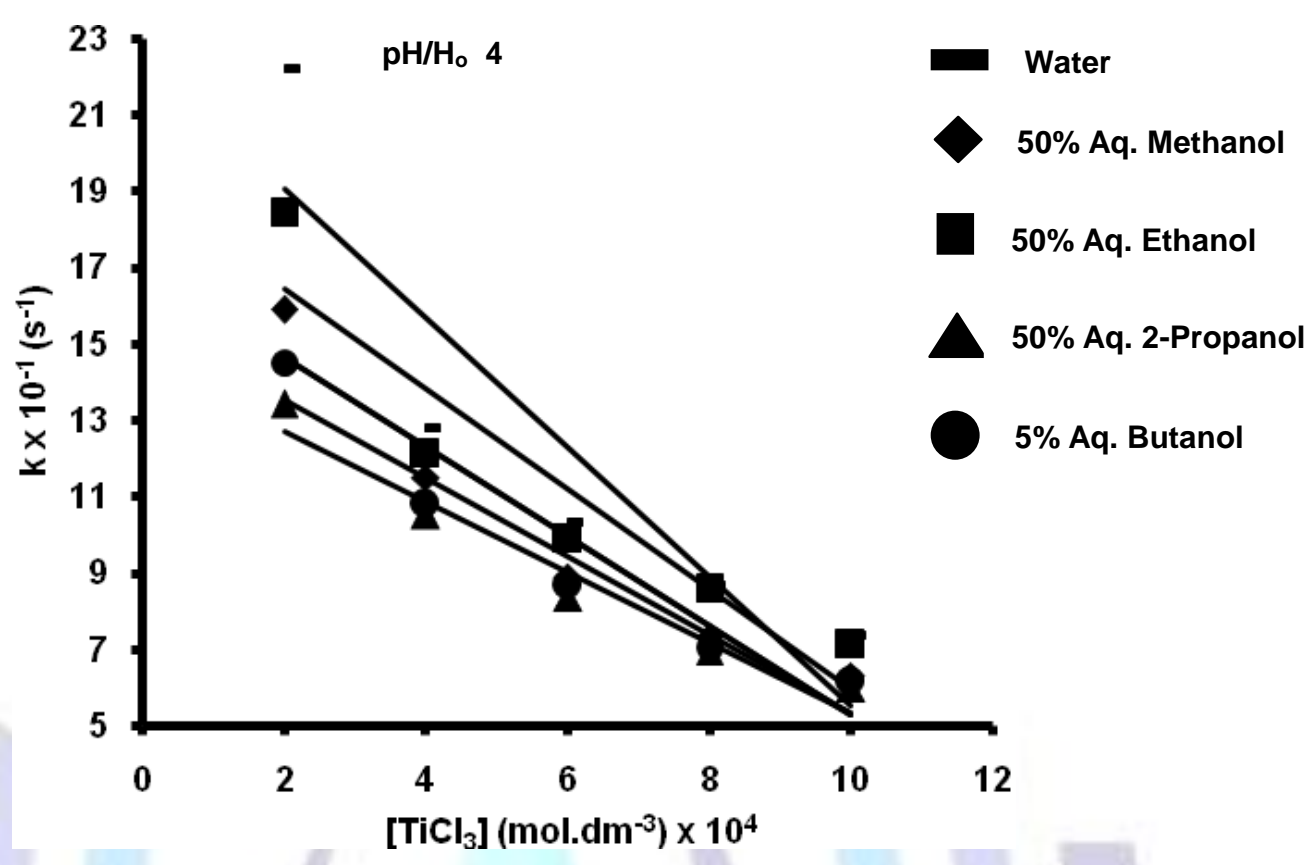

Figure 9. A plot of the rate constant vs concentration of titanium trichloride in different Solvents

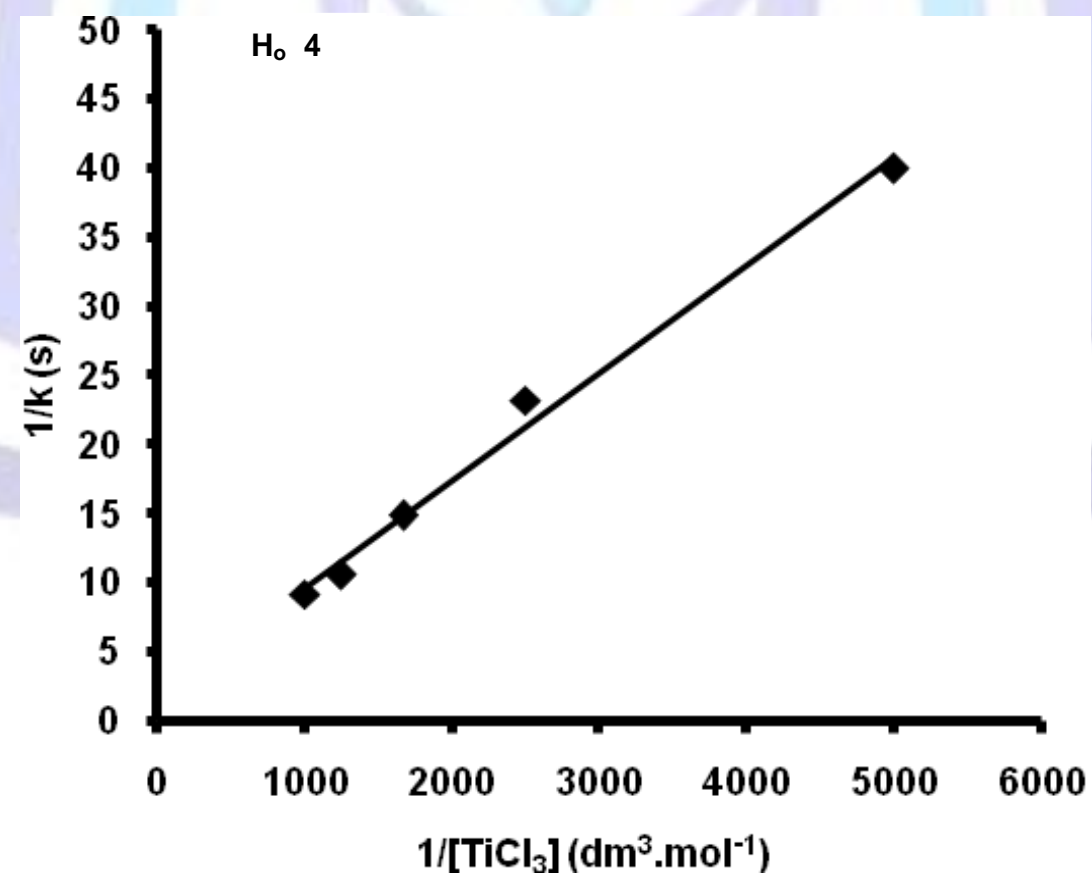

Figure 10. Michealis-Menten plot for the electron transfer reaction of $\mathrm{MB}^{+}$and $\mathrm{TiCl}_{3}$ in $50 \% \mathrm{Aq}$. Methanol at $298 \mathrm{~K}$ 


\subsection{Stoichiometry of Reaction}

The mole ratio of the electron transfer reaction between methylene blue and titanium trichloride was determined by spectrophotometric titration and it was found that one mole of methylene blue reacts with one mole of titanium trichloride.

$\mathrm{MB}^{+}+\mathrm{TiCl}_{3} \underset{2 \mathrm{e}^{-}}{\stackrel{2 \mathrm{H}^{+}}{\longrightarrow}} \mathrm{MBH}_{2}^{3+}+$ Secondary Products

Based upon the absence of any intermediate species formation, the following outer-sphere mechanism has been suggested for the reaction. The reactions involved in the liberation of protons by the reaction between titanium trichloride and water molecules are as follows.

$2 \mathrm{TiCl}_{3} \longrightarrow \mathrm{TiCl}_{4}+\mathrm{TiCl}_{2}$

$\mathrm{TiCl}_{4}+2 \mathrm{H}_{2} \mathrm{O} \longrightarrow 4 \mathrm{HCl}+\mathrm{TiO}_{2}$

$4 \mathrm{HCl}$

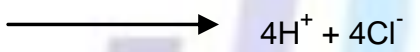

(6)

\subsection{Reaction Mechanism}

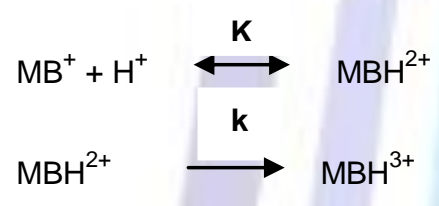

(7)

(8)

From Eq. (7) $\mathrm{K}=\left[\mathrm{MBH}^{2+}\right] /\left[\mathrm{MB}^{+}\right]\left[\mathrm{H}^{+}\right]$

Therefore,

$\left[\mathrm{MBH}^{2+}\right]=\mathbf{K}\left[\mathrm{MB}^{+}\right]\left[\mathrm{H}^{+}\right]$

The possibility of triply protonated form of methylene blue has been excluded because the reaction has not been performed in strongly acidic medium. However, since the protons involved in the reaction get liberated from the reaction of $\mathrm{TiCl}_{3}$, so the reaction rate can be expressed as:

$\mathrm{MB}^{+}+\mathrm{TiCl}_{3} \stackrel{\mathbf{k}_{\mathbf{1}}}{\longrightarrow}\left[\mathrm{MB}^{+}, \mathrm{TiCl}_{3}\right]$
$\mathrm{MBH}^{2+}+\mathrm{TiCl}_{3} \stackrel{\mathbf{k}_{\mathbf{2}}}{\longrightarrow}\left[\mathrm{MBH}^{2+}, \mathrm{TiCl}_{3}\right]$

From Eq. (10) and (11), the rate law can be written as:

Rate $=\mathrm{k}_{1}\left[\mathrm{MB}^{+}\right]\left[\mathrm{TiCl}_{3}\right]+\mathrm{k}_{2}\left[\mathrm{MBH}^{2+}\right]\left[\mathrm{TiCl}_{3}\right]$

From Eq. (9), put the value of $\left[\mathrm{MBH}^{2+}\right]$ in Eq. (12): 
Rate $=\mathrm{k}_{1}\left[\mathrm{MB}^{+}\right]\left[\mathrm{TiCl}_{3}\right]+\mathrm{k}_{2} \mathrm{~K}\left[\mathrm{MB}^{+}\right]\left[\mathrm{H}^{+}\right]\left[\mathrm{TiCl}_{3}\right]$

Rate $=\left[\mathrm{TiCl}_{3}\right]\left[\mathrm{MB}^{+}\right]\left(\mathrm{k}_{1}+\mathrm{k}_{2} \mathrm{~K}\left[\mathrm{H}^{+}\right]\right)$

Let $k=\left(\mathrm{k}_{1}+\mathrm{k}_{2} \mathrm{~K}\left[\mathrm{H}^{+}\right]\right)$, then

Rate $=k\left[\mathrm{TiCl}_{3}\right]\left[\mathrm{MB}^{+}\right]$

Since rate of reaction was determined at a constant concentration of methylene blue, therefore

Rate $=k\left[\mathrm{TiCl}_{3}\right]$

The $\mathrm{H}^{+}$ions produced upon dissociation of $\mathrm{HCl}$ are responsible for the reduction of methylene blue to leuco-methylene blue, while the $\mathrm{TiO}_{2}$ forces the reaction in backward direction by simultaneous oxidation of leuco-methylene blue. The present reaction was studied only for the reduction of methylene blue to leuco-methylene blue.

\subsection{Thermodynamic Parameters}

The energy of activation for the electron transfer reaction of methylene blue and titanium trichloride was determined by using Arrhenius equation:

$k=A e^{-E a / R T}$

Where $R$ is the gas constant, $E_{a}$ is the energy of activation, $A$ is the frequency factor, $k$ is the rate constant and $T$ is the temperature [4, 7]. The activation energy was calculated from the slope of the plot of $\ln \mathrm{k}$ vs $1 / \mathrm{T}$. A representative plot is shown in Figure 11. The energy of activation was affected by the polarity of the solvent and concentration of titanium trichloride. The energy of activation decreased with decrease in polarity of the solvent due to the less hinderance in less polar solvent which increased the number of collisions between the reactant species. In a medium of low polarity, the charged activated complex is only slightly solvated and less amount of energy required for its conversion into products; the activation energy gets decreased.

The enthalpy change of activation $\left(\Delta \mathrm{H}^{*}\right)$, entropy change of activation $\left(\Delta S^{*}\right)$ and free energy change of activation $\left(\Delta \mathrm{G}^{*}\right)$ were calculated by the Eq. (18-20).

$\Delta H^{\star}=E_{a}-R T$

$\ln A=\ln \left(K_{b} T / h\right) \times \Delta S^{*} / R$

$\Delta \mathrm{G}^{*}=\Delta \mathrm{H}^{*}-\mathrm{T} \Delta \mathrm{S}^{*}$ 
Where $A$ is the frequency factor evaluated from the intercept of the Arrhenius plot of In $k$ vs $1 / T$, $h$ is the Plank's constant and $\mathrm{K}_{\mathrm{b}}$ is the Boltzmann constant. The enthalpy change of activation $\left(\Delta \mathrm{H}^{*}\right)$ decreased with the decrease in the polarity of the medium. The very small entropy change of activation suggests that the activated complex most probably involves ions of similar charges giving a greater net charge to the activated complex as compared to individual ions before activation. This increased charge causes the orientation of solvent molecules around the activated complex [4]. The free energy change of activation $\left(\Delta G^{*}\right)$ decreased with decrease in polarity of the solvent. The values of thermodynamic parameters are tabulated in Table 4.

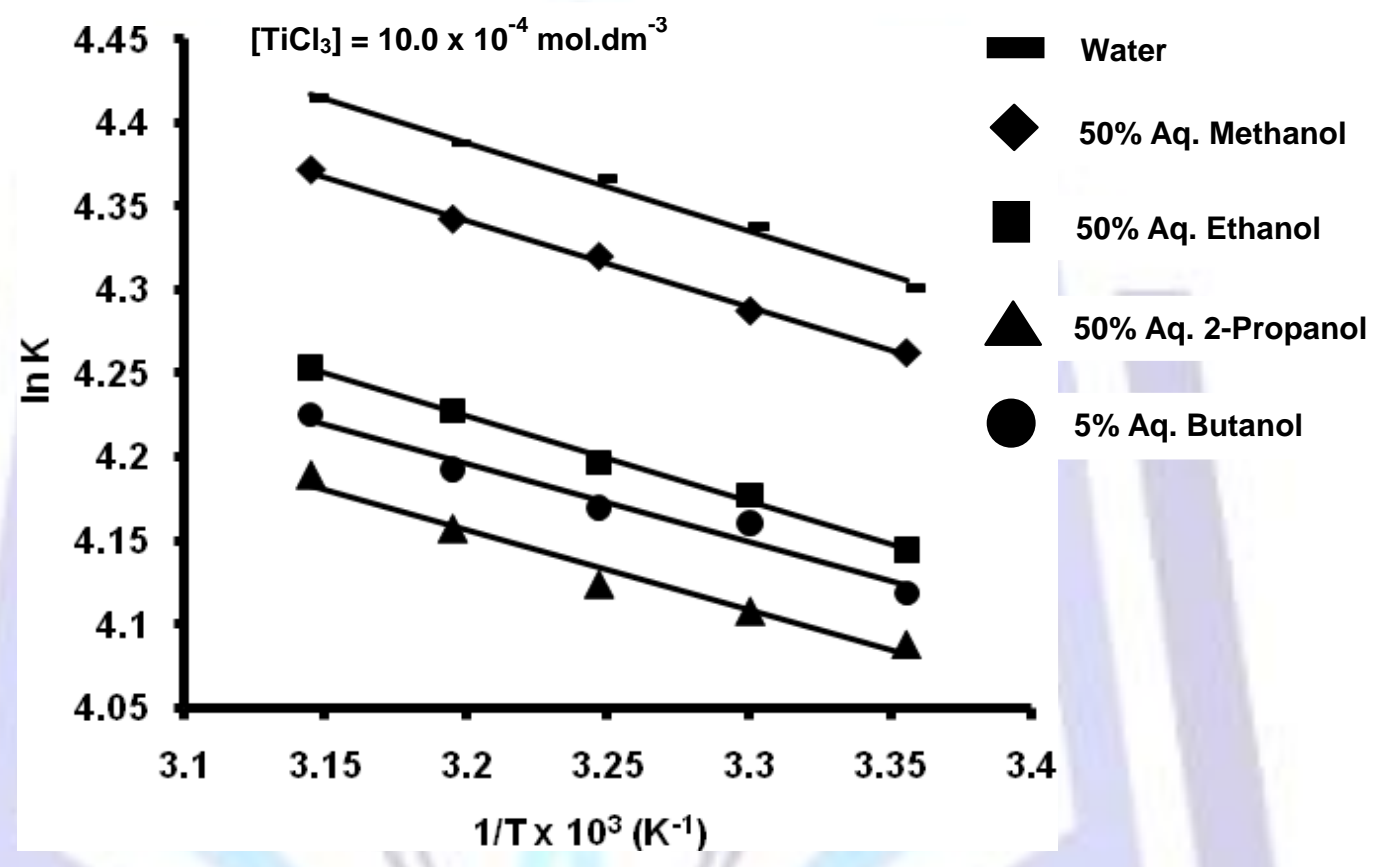

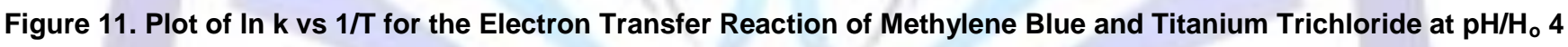

Table 4. Thermodynamic parameters for the Electron Transfer Reaction in different solvents at $\mathrm{pH} / \mathrm{H}_{\mathrm{o}} 4$

\begin{tabular}{|c|c|c|c|c|}
\hline Solvent & $\mathrm{E}_{\mathrm{a}}\left(\mathrm{J} . \mathrm{mol}^{-1}\right)$ & $\Delta \mathrm{H}^{*}\left(\mathrm{~J} . \mathrm{mol}^{-1}\right)$ & $\Delta \mathbf{S}^{*}\left(\mathrm{~J} \cdot \mathrm{mol}^{-1} \cdot \mathrm{K}^{-1}\right)$ & $\Delta \mathbf{G}^{*}\left(\mathrm{~J} . \mathrm{mol}^{-1}\right)$ \\
\hline Water & 4376 & 1898 & 1.71 & 1390 \\
\hline $50 \%$ Aq. Methanol & 4250 & 1772 & 1.65 & 1280 \\
\hline $50 \%$ Aq. Ethanol & 4307 & 1829 & 1.69 & 1320 \\
\hline $50 \%$ Aq. 2-Propanol & 3859 & 1381 & 1.61 & 903 \\
\hline $5 \%$ Aq. Butanol & 3987 & 1509 & 1.60 & 1030 \\
\hline
\end{tabular}




\section{CONCLUSION}

The electron transfer reaction of methylene blue and titanium trichloride was found to be a pseudo-first order reaction. The reaction followed first order kinetics with respect to titanium trichloride at constant concentration of methylene blue. The rate of reaction was strongly influenced by the hydrogen ion activity of the reaction mixture, polarity of the solvent and the concentration of titanium trichloride. The increase in polarity of the solvent decreased the intensity of the absorption band of methylene blue and caused a hypsochromic shift in the absorption spectrum. The absence of any intermediate formation was confirmed by Michealis-Menten plot which gave a positive intercept. The positive values of entropy change of activation $\left(\Delta S^{*}\right)$ and free energy change of activation $\left(\Delta G^{*}\right)$ showed that the formation of activated complex is between ions of similar charges. The reaction occurred through outer-sphere mechanism.

\section{REFERENCES}

1) Galagan,Y., and Su, W. F. J. 2008. Photochem. Photobio. A: Chemistry, 2008, 195: 378.

2) Katafias, A., Kita, P., and Wrzeszcz, G. 2006. Transition Metal Chem. 2006.

3) Kobasa, I. M., Kondrat'eva I. V., and Gnatyuk, Y. I. 2008. Theoret. Exp. Chem. 44: 42.

4) Saeed, R., Uddin, F., and Khalid, Z. 2004. Turk. J. Chem. 28: 351.

5) Ahmed, T., Azmat, R., and Uddin, F. 2004. Turk. J. Chem. 28: 351.

6) Azmat, R., and Uddin, F. 2009. Chi. J. Chem. 27: 1237.

7) Saeed, R., Ashfaq, M., and Razi Khan, S. R. 2010. Asian. J. Chem. 22: 1787.

8) Wu, C. H., and Chern, J. M. 2006. Ind. Eng. Chem. Res. 45: 6450.

9) Randorn, C., Wongnawa, S., and Boonsin, 2004. Sci. Asia. 30:149.

10) Mohabansi, N. P., Patil V. B., and Yenkie, N. 2011. Russ. J. Chem. 4: 814.

11) Bevilaqua, T., Goncalves, T. F., Venturini, C. D. G., and Machado, V. G. 2006. Spectrochim. Acta Part A. 65: 535.

12) Dave, M. D., and Pande, U. C. 2013. Chem. Sci. Trans. 2(3): 749.

13) Mahmood, T., Mahmood, I., Mustafa, S., and Ahmad Ali, A.. 2013. Europ. Acad. Res. 1(5): 701.

14) Kataria, B. 2008. Int. J. Chem. Sci., 6: 1676.

15) Osunlaja, A., Adekunle, Idris, S. O., and lyun, F., J. 2012. Der Chemica Sinica, 3: 1428.

16) Osunlaja, A. A., Idris, S.O., and lyun, J.F. 2012. Int. J. ChemTech Res. 4: 609. 